\title{
Flood susceptibility mapping using integrated bivariate and multivariate statistical models
}

\begin{abstract}
Flooding can have catastrophic effects on human lives and livelihoods and thus comprehensive flood management is needed. Such management requires information on the hydrologic, geotechnical, environmental, social, and economic aspects of flooding. The number of flood events that took place in Busan, South Korea, in 2009 exceeded the normal situation for that city. Mapping the susceptible areas helps us to understand flood trends and can aid in appropriate planning and flood prevention. In this study, a combination of bivariate probability analysis and multivariate logistic regression was used to produce flood susceptibility maps of Busan City. The main aim of this research was to overcome the weakness of logistic regression regarding bivariate probability capabilities. A flood inventory map with a total of 160 flood locations was extracted from various sources. Then, the flood inventory was randomly split into a testing dataset $70 \%$ for training the models and the remaining $30 \%$, which was used for validation. Independent variables datasets included the rainfall, digital elevation model, slope, curvature, geology, green farmland, rivers, slope, soil drainage, soil effect, soil texture, stream power index, timber age, timber density, timber diameter, and timber type. The impact of each independent variable on flooding was evaluated by analyzing each independent variable with the dependent flood layer. The validation dataset, which was not used for model generation, was used to evaluate the flood susceptibility map using the prediction rate method. The results of the accuracy assessment showed a success rate of $92.7 \%$ and a prediction rate of $82.3 \%$.
\end{abstract}

Keyword: Bivariate probability; Busan; Flood susceptibility; GIS; Logistic regression 